\title{
THE CONCEPT OF CLASS: A MULTILEVEL APPROACH
}

\author{
MLADEN LAZIC
}

\begin{abstract}
Most controversy that arises around the concept of class is a consequence of the fact that protagonists do not differentiate the level of abstraction at which the discussions take place. Namely, the definition of the concept of class essentially depends on the analytical level at which social phenomena are analyzed. Therefore, it must be defined differently at different analytical levels. It is necessary to distinguish at least four such levels in societal analyses: social formation, historical system, concrete-historical society, and the reproduction of everyday life. At the most general level (capitalism, for example,) classes are established on the basis of the control of overall social resources, and their relations thus appear as antagonistic (dichotomous model). At the historical system level, the totality of control branches into domination over economic, organizational, and cultural resources, and the unified body of class is broken up into strata, including also some differentiation of intraclass interests. At the level of concrete-historical society, further intra- and inter-class differentiation develops, and classes appear as internally divided and potentially conflicted entities. At the level of everyday life, the central subject of research is individuals, whose class membership must be analytically reconstructed, which is the field of operation of empirical sociology.
\end{abstract} KEYWORDS: social class, analytical levels, social formation, historical system, concrete society, everyday life

\section{INTRODUCTION}

Controversy related to the concept of class has persisted for over 150 years if we date the beginning of the former phenomenon to Marx and Engels' renowned

1 Mladen Lazic is a professor at the University of Belgrade; e-mail: bigalazi@eunet.rs 
work The Communist Manifesto (2012). In this book, as is well known, historical changes are interpreted as a result of class conflict involving-at all levels of social development-two antagonistic classes (slaves and slave-owners, feudalists and serfs, bourgeoisie and proletariat). This simple view served as the starting point for those who denied the very validity of the class concept, as well as to quite a few who accepted the concept. Naturally, the latter group displays significant differences in terms of the stress they place on the specific dimensions upon which social antagonisms are formed (e.g. differences between those who have attributed the foundation of classes primarily to economic, political, or cultural factors, or their various combinations).

The above-mentioned controversies however, derive from the fact that participants in relevant debates as a rule fail to grasp that differences between particular approaches to class analyses are due to a simple epistemological oversight: in these debates, classes are defined at essentially different analytical levels. That is why this text will seek to indicate these different levels and stress the need to see that in analytical procedures this concept is defined differently as well as mutually consistently at each of these levels, or that at least attention is paid to the level at which the analysis is carried out (i.e. to the existence of different levels). ${ }^{2}$ This kind of clarification could, I believe, dispense with both a substantial number of futile discussions between authors concerned with class analysis and part of the censure of those whose criticism of the concept of class relies on its unjustified extension to other analytical levels of objection relevant to a particular one (i.e. by claiming, for example, that the two-class model of society, which appears at the abstract analytical level of social formation, must be rejected due to the empirical complexity arising in concrete historical circumstances).

Accordingly, the first part of the text will summarize some of the currently most influential and largely different views in relation to class analysis and warn of the difficulties deriving from the above-mentioned epistemological oversight. Goldthorpe's reliance on Weber's market dimension of class differentiation results in the disappearance of the ruling class from his class scheme, as well as in the merging of different analytical levels (social formations and concrete historical societies). This leads him to an erroneous conclusion about the universal level of fluidity in contemporary (capitalist, and at that time also socialist) societies (Marshall 1997: 7-10). E. O. Wright in his most recent works reveals an awareness of the differences between analytical levels, but fails to make the different definitions of the concept of class developed in

2 The existence of different analytical levels in Marx's historical analysis is pointed out by Sztompka (1994: 157-173). 
his work mutually consistent, or to establish a systematic link between them (Wright 2015). Finally, Savage, in his most recent works, hinges his analysis on a fundamental epistemological error, believing in the possibility of (statistically) reconstructing the concept of class at higher levels of abstraction (concretehistorical society, historical system) starting from direct empirical insights into everyday life (Savage, M. et al. 2013).

The main body of this text indicates the existence of (at least) four analytical levels on which the concept of class appears. These are: social formation, historical system, concrete historical society, and the reproduction of everyday life. ${ }^{3}$ Then, mutually consistent but different concepts of class are formulated at each of these levels, accompanied by statements of varying bases concerning social divisions existent in each one of them. It will be shown that these bases differ with respect to the different forms of integration of the main resources upon which the social reproduction rests: economic, political, and cultural. In other words, it will be revealed that forms of the material reproduction of society, regulation/control of hierarchical social integration, and symbolic communication are systemically integrated into different social formations in different ways, where at the most abstract analytical level all resources are under absolute control of the ruling class (the two-class model), followed by the increasing relativization of this control at more concrete analytical levels (multiclass model, intra-class differentiation, etc.).

A brief conclusion summarizes the main findings by indicating that the concept of class, discriminatingly but mutually consistently defined, is valid at each of analytical levels providing that - if used at only one of these levels - it pays heed to the entire analytical "field" it covers.

\section{CONTEMPORARY VIEWS OF CLASSES: A BRIEF OVERVIEW}

The previous period of the cyclical ascent of capitalism, the culmination of which in the 1990s was designated as "the end of history" (Fukuyama 1992), was short lived. It was primarily marked by the seemingly unstoppable advance of globalization, which ushered into the dominant social-economic order such countries as China and Russia, to mention but the largest among them. At the theoretical level, attention shifted from general questions concerning the nature of that order towards more concrete studies of its variants ("variants of

3 Sztompka differentiates three levels: action-individual, socio-structural, and world-historical level (Sztompka 1994). 
capitalism"). In line with this focus on the specific and individual, the nominalist approach to social analysis has become almost universally accepted.

This harmony was however disrupted by the dramatic economic crisis of 2008 which had global proportions, just as with the previous stage of ascent. Since we are primarily interested in the analytical apparatus used by social theory, we will only note that the viewpoints which speak of deep economic divisions between different groups in the population have once again become the focus of attention, occasionally reaching the scale of planetary bestsellers as was the case with Picketty's book (2014). Furthermore, the theoretical legitimacy of the idea of the division of society into classes as groups which due to their structural position have potentially conflicting (or even antagonistic) relations and therefore represent the key feature of modern society has also been restored. This is why, looking backwards, it may now be easier to see that, despite its largely blocked development, this particular view was also present and even influential in the previous period - for example, in mobility studies (Erikson and Goldthorpe 1992; for a recapitulation of different contemporary approaches to class analysis see E.O. Wright ed. 2005).

The delay in the development of a class approach to social analysis had two sources: external criticism, and the vagueness of certain epistemological assumptions in the approach itself. We will not extensively dwell on the former factor since this was widely addressed during the well-known discussion about the relevance of the concept of class (for a systemized approach, see Crompton 2008). In brief, those who deny the concept of class relevance in social analysis may initially be divided into two groups. The first includes authors who believe that this concept has never been scientifically founded and that its use was primarily ideological. The second comprises those who claim that class as a form of social grouping has lost its historical relevance. Extensive discussion of the arguments proposed by authors in the first group would here be pointless because the relevant debate may be resolved on the basis of overall scientific contributions that are attributable to specific approaches. As for the critics who emphasize the historical obsoleteness of the class concept, their starting point is the following: The heuristic value and even epistemological foundation of this concept started to disappear following the last quarter of the twentieth century due to deep changes within post-industrial, disorganized capitalism. Hierarchies in modern society are constituted in a remarkably multidimensional and fragmented way. Therefore, none of these dimensions can any longer retain a structurally deterministic role. Economic inequalities, regimes of social mobility, value and political orientations allegedly all undergird the former class barriers (Lash 1990; Beck 1992; Pakulski and Waters 1996).

Opposed to inferences of this kind are authors who argue that the concept of class maintains the central role in the interpretation of current social, economic, 
political and cultural processes in present-day societies. With this, they also invoke the developed programs of empirical research. ${ }^{4}$ Most of these authors can be divided into two uneven subgroups. The more numerous among them build their understanding of class following Weber, claiming that classes are formed on the basis of the substantially different positions individuals occupy on the labour market, the nature of their labour contracts, employment stability, level of income, etc. The most prominent author in this theoretical stream is Goldthorpe (1996; 1999; 2000/2007; Chan and Goldthorpe 2007). His class scheme has provided the basis for a large number of pieces of empirical research focused primarily on the problem of social mobility, but also the voter orientations of members of different classes, cultural consumption, etc. What gives particular importance to this orientation is the remarkable rigorousness of research procedures in the approach to conceptual operationalizations, the collection of data, and the statistical techniques for their processing. There is no doubt that the sociological analysis in the work of those who share this view has come quite near to the contemporary understanding of an empirically founded, contestable scientific theory (Nagel 1961).

Although a more detailed critical examination of Goldthorpe's approach is here impossible (it is known widely enough, and requires no comprehensive explanation), some observations should still be made. Construed primarily for the study of vertical mobility and deliberately kept at the level of a "middlerange theory," the proposed class scheme starts from a view which lacks a complete conceptual basis and, moreover, has not been empirically verified in a more extensive and systematic manner. More precisely, authors who use it make no attempt to answer the question which inevitably precedes it: which particular social processes produce the inequality of market chances as the basis for the empirically identified differentiation of the working situations of individuals grouped into social classes? ${ }^{5}$ In other words, social formation as an analytical level is completely absent from this theoretical concept, while the second and the third levels (historical system, concrete-historical society) appear undifferentiated.

4 Marshall objects to those who criticize the usability of the concept of class in contemporary conditions due to the fact that their theses are primarily declarative and unfounded in systematically collected data, in contrast to supporters of the class approach who also tend to seek an empirical foundation for their views (Marshall 1997: 13-18).

5 Research programs which depart from Goldthorpe's class scheme as a rule leave out the wider thematization of the economic inequalities of social groups. In terms of content, these programs focus on the (statistical) link between the central category of this approach-occupation, and mobility - and thus also the degree of education, voter orientation, and income (Goldthorpe and McKnight 2004; Goldthorpe 2007; Crompton 2008). 
Geared more towards research than the theoretical sphere, this class scheme has subjected its form to research techniques (at the most concrete analytical level of everyday life). Its top social ranks include the "service class" (in later works, the "salariat") groups - considered substantially different by the majority of stratification theorists - such as middle- (e.g., professional) and higher strata individuals (higher-level managers, and owners of large and medium-size firms). ${ }^{6}$ The reason invoked for this coupling - underrepresentation of the latter groups in proportional samples used as a rule in sociological research - itself indicates program-related difficulties with this approach. The "drowning" in the widest middle stratum of that part of the dominant social groups who essentially control the economic conditions of social reproduction is not only problematic from a theoretical point of view but also from an empirical one, which the advocates of Goldthorpe's class scheme cherish the most. Namely, this leaves in the dark the recruitment patterns of precisely that class which present the greatest analytical challenge to research. ${ }^{7}$ The practical consequences of this approach, as well as its cognitive limits, are well illustrated by the claim that empirical analyses represent fluidity in developed industrial societies as basically equal, and that therefore there has been no significant difference in mobility between formerly socialist and capitalist countries (Marshall 1997: 7-10). This conclusion is basically incorrect, precisely because the dominant class in socialism was substantially more open than its capitalist "cousin" (Lazic and Cvejic 2007).

Another variant that defends the relevance of a class approach in the study of modern society is the perspective of E. O. Wright (1978; 1985; 2015; Wright et al. 1989; Wright ed. 2005). Based originally on a neo-Marxist interpretation of capitalist social relations and theoretically (deductively) developed, and then operationalized and applied in empirical research, it has led to problematic theoretical results as well as unconvincing empirical findings. Briefly, Wright's view underwent three stages of development. In the first one, he started with production relations and distinguished three basic classes in capitalism: bourgeoisie, proletariat, and petty bourgeoisie (an insight which does not relate to the first, most abstract analytical level, the concept of capitalism, but to the second level of the historical system). According to Wright, class positions are,

6 Authors speak of the social top conditionally, since they insist on the scheme being relational rather than hierarchical. However, the fact that the service class is in every respect superior to all other classes is indisputable to such a degree that it is explicitly referred to by the authors themselves. They, namely, conditionally hierarchise the scheme in order to introduce "the dominance approach" into the identification of the class positions of respondents (Erikson and Goldthorpe 1992: 265277).

7 The absence of the top of a class hierarchy in Goldthorpe's scheme is criticized in Savage et al. (2013). 
in real relations, revealed as jobs rather than occupations. Within the structure of jobs, class relations are manifested as differences between individuals with respect to degree of ownership, control and autonomy. Since in these dimensions inequality is manifested gradationally - as a higher or lower degree of control, autonomy, etc.- -in addition to the three basic class positions in the overall social space, we also find "contradictory class positions." This is why three additional classes are introduced into the class scheme: managers and foremen; small employers; and semiautonomous wage workers (which brings us to the third analytical level of concrete society). Applied in empirical research, this scheme led to the proliferation of holders of contradictory positions, so that the basic class in capitalism, the proletariat, became a minority group (Wright 1985: 84).

Dissatisfied with his own original scheme, Wright introduced important changes in the new version. In place of domination as the central category of class relations, he introduced exploitation, which is in different societies based on specific types of ownership of: labour (feudal); capital (capitalist); organization (statist); and education (socialist). The last three forms of ownership are also present in modern capitalism, and their intersections on the new class map gave rise to twelve classes (Wright, 1985: 88).

It is clear that within this viewpoint the non-systemic intertwining of diverse analytical levels is even more pronounced. Furthermore, this solution fails to remove the previous difficulties with the approach, and may have even increased them. On the conceptual level, departing from the concept of domination as the centre of differentiation and substituting it with that of exploitation interpreted on the basis of game theory, it essentially approached the view of market-based class relations. Game theory, namely, implicitly assumes the voluntariness of participation. In contrast, within class relations the rules of the game themselves are determined by dominant players while subordinates cannot opt out or choose another game in which their position would be substantially different. ${ }^{8}$ At the level of operationalization, the proletariat as one of the basic classes disappears even more in extensive differentiations. This way, the constitutivity of this class for the capitalist process of production becomes problematic. Wright himself saw difficulties in the explicative potential of this view for the analysis of the available empirical material. He thus explains the further dwindling of the proletarian class in American society with reference to the advancement of the process of globalization, which relocates proletarians to Third World countries, turning the class structure of the USA into a predominantly managerial one (Wright and Martin 1987).

8 Using Durkheimian terminology one may say that Wright here does not take into account the "noncontractual bases of contracts" which he invokes in his recent work (2015: 177). 
Finally, in a recent work Wright uses an approach which at first glance seems very close to the one we will suggest in this paper, stating that "class and its related concepts can be analysed at various levels of abstraction" (Wright 2015: 189). These levels are determined differently in different chapters of the book, as: a) "micro and macro aspects of economically rooted inequality in capitalist societies" (p. 2); b) "three clusters of questions" relevant for the analyses of these inequalities - domination and exploitation (control of the means of production), control of economic resources (property rights), and individual attributes of people occupying specific class locations (pp. 3-7); c) class relations, location and structure, class structuration and formation, and collective class actors ( $\mathrm{p}$. 94); and d) system level, institutional level, and situational level (p. 120). The most important point Wrights makes is, however, that the conceptual apparatuses adequate for analyses of these "different aspects of class structure" have been developed by different theoretical traditions: (neo)Marxist, (neo)Weberian, and stratificational, which makes these traditions complementary and "not mutually exclusive" (p. 12).

The problem with Wright's late approach is that, while he rightly points out the need to "develop a coherent, consistent way of theoretically understanding social cleavages and possibilities of transformation" (p. 173), he fails to demonstrate how we can conceptually reconcile the competing theories (or, in other words: how can different analytical frameworks be linked; and which of the above-mentioned analytical frameworks should be used?). Namely, what he only tries explicitly to show is that at some analytical points discrepancies between Marxist and Weberian analyses are less deep than the protagonists of these approaches try to demonstrate. In this way his "reconciliation" inevitably remains eclectic. Additionally, his insistence on the sole economic foundations of class relations, the limitation of class phenomenon to capitalist societies, and the methodological usefulness of game theory as an instrument of class analysis mean that Wright's attempt at integrating different theoretical traditions is far from a synthetic approach and much closer to a (neo)Weberian orientation.

Finally, we should also mention an approach which in its foundation of class analysis seeks to reach beyond the frameworks of previous theoretically based orientations (neo/Marxist, neo/Weberian etc.), and which looks for a mainstay in empirical research material. This refers to authors who believe that the statistical processing of data about various dimensions of individual inequalities may produce insight into the systemic groupings of these inequalities, which may then be attributed the quality of "classness." A recent attempt of this kind is that of M. Savage and a group of authors (Savage et al. 2013; Savage et al. 2015), who, on the basis of a latent class analysis propose a new "multi-dimensional model of social class." Their class scheme is developed on the basis of research 
into indicators of economic, social and cultural capital (construed on Bourdieu's categories). Their latent analysis "produced" seven classes, with the elite on the top, two subgroups of the middle class, three working classes, and a precariat at the bottom of the pyramid (2013: 12; 2015: 165-181).

This more recent attempt at "inductive analysis," however, obviously cannot overcome the already mentioned problem: that theoretical concepts (types of capital/resources, a list of indicators, etc.) are necessary for the premise of the research itself, and therefore predetermine the statistically obtained categories. ${ }^{9}$ In addition, it must be kept in mind that Bourdieu's categories are explicitly relational (Bourdieu 2002), as opposed to Savage's class hierarchy which is not, and can hardly be (moreover, authors do not seek to present it as such). The most conspicuous deficiencies of this scheme-for example, the arbitrariness of the division into subgroups, and theoretically illogical features in the "distribution" of both the forms of capital (2013: 12) and "socio-demographic correlates" (2013: 13) - are here of lesser importance than methodological problems stemming from the manner of founding the theoretical view on class relations. Namely, the objective Savage set for himself - to induce theoretical insights into class structure-rests on a fundamental epistemological error: the concept is not the final but rather the starting point of the analysis. The concrete cannot arrive at the concept because without a concept is appears as pseudo-concrete. ${ }^{10}$ To wit, empirical research at the level of everyday life cannot be conducive to the most abstract analytical level, but the path must be reversed: from a concept towards facts (precisely how Savage himself started his book with Bourdieu's categories, only to subsequently "forget" this beginning).

\section{TOWARD A CONCEPTUALLY DIFFERENTIATED APPROACH TO THE CONCEPT OF CLASS}

\section{Basic analytical levels}

The purpose of the above discussion was to give a brief introduction to a conceptually more differentiated manner of establishing the perspective of

\footnotetext{
9 On the devastating theoretical and methodological critique of the GBCS data upon which Savages's analysis is based, see e.g. Mills 2014, 2015. See also the special issue of The Sociological Review (2015).
}

10 Kosik 1976; 40. For more details, see the explanation below. 
classes as groups whose relations are crucial for the reproduction of a given social system and its change. If one of the main areas of sociological analysis is the establishment of principles on the basis of which a society is reproduced and changed, than the focus of such research must clearly be on the old and new social relations which form the so-called structures, on the one hand, and on the other, the very process of their change (i.e. the agents of these changes: actors). This approach begs the following question: what precisely are classes in these processes of reproduction and change: structures or actors, or both structures and actors?"1

The assumption that classes, or more precisely their relations, form structures will hardly be questioned by anyone who accepts the validity of the concept itself. Class relations are, according to different authors, constituted on the basis of economic structures (Weber 1978), power structures (Dahrendorf 1959), cultural practices (Gramsci 1971), or all of the above taken together: on the system of re/production of overall social life (Marx 2005). There is no need to dwell on this point, as it stands or falls with the basic approach to overall social problems. The second point, however, requires somewhat more extensive commentary, knowing that even those authors who accept the class concept as a valid analytical category deny it the possibility of representing an active historical subject. Such is the view of Weber, as well as Giddens and many other ("nominalist") authors. The former has been incorporated into various influential modern theoretical orientations such as symbolical interactionism.

Consideration of this issue will start with a more or less generally endorsed statement. Every sociological perspective, regardless of its basic theoretical assumptions (whether it accepts the analytical validity of using the class concept or not), includes, explicitly or implicitly, at least an elementary conception of the specific nature of social groups, according to which their existence is relatively autonomous from the individuals who form it. Suffice it to recall the trivial joint assumption: namely, that a group as a specific unit may be reproduced, the changed composition of its members notwithstanding. If that assumption is brought into doubt, the very notion of society would a fortiori have to be declared an empty abstraction, or discarded altogether. In this way, sociology itself would lose the status of a relatively autonomous science and revert to the sphere of social philosophy, or else be reduced to social psychology (the examination of exclusively interpersonal relations).

Contrarily, the very process of the constitution of sociology as a scientific discipline during the twentieth century developed in firm opposition to the

11 The fact that the latter question is not an empty paradox has long been proposed by Giddens, who insists on self-reflexivity as the key component of human action (1995: 41-109). 
previous social-philosophical tradition through the consolidation of its empirical orientation. During this process, as a rule, many authors - from Durkheim to the neofunctionalists - overemphasized the positivistic-empiricistic foundation of this discipline. Starting from a remarkably firmly formulated view (that structures are things [Durkheim 1982]), this development led to empirical studies wherein units of observation are inevitably individuals or small groups (organizations, etc.). On the other hand, with the increasingly stronger forms of criticism of structuralism, and reified relations as subjects of sociological research, interpersonal relations were declared the only real forms of human social existence. This is how a seemingly unbridgeable breach between collective and individual forms of manifesting sociality opened up. At this, collective forms were either denied or reduced to mere abstractions as in the seemingly paradoxical view of Giddens that structures may influence but groups cannot act.

The ostensible paradox was resolved by defining the concept of action in a restrictive Weberian tradition. Its determination was subject to conditions which, by definition, excluded its collective forms: human action was defined as an interpersonal relation, because it postulated a "subjective meaning" according to which the actor was "oriented" (Weber 1978, 1: 4). In line with this approach, forms of sociality with Weber can in this case appear only as "ideal types." The problem with this perspective for the study of patterns of social reproduction, and especially social changes, lies in the fact that the ideal-typical approach freezes the opposites of the two historical phenomena. It antagonizes them to mutual exclusion and thereby methodically implies a static relation towards reality. This is why the ideal-typical method is unsuitable for researching the processuality of historical change in the overall social sphere, wherein existing basic social relations are over time reconstructed into relations established on different bases through the process of action of basic social actors.

The problem of mediation between categories - collectivities/groups (social) and individuals (individual) - is highly complex and cannot be systematically examined here. But, with a view to a brief and illustrative presentation of this problem, and taking Weber as the example, we should recall the whole series of concepts he introduced as mediators between the concept of capitalism as the social order and the ideas of Martin Luther: the capitalist economy, factions of the bourgeoisie (monopolists, speculators, bankers), political movements (puritans, levellers), religious denominations, organizations and movements (Catholics, Anglicans, Lutherans, Calvinists), capitalist ethics, the ethics of religious groups, mentalities (individual, group), interests (economic, political; collective, individual), etc. (Weber 2003). It is quite obvious that the list of mediating categories is in principle inexhaustible. Moreover, its initial, abstract, 
and finally empirically verifiable points, as well as the conceptual sequence between these two (the number and contents of mediating notions) depend on the problem that is addressed. Successful sociological interpretation of a social phenomenon implies precisely the merging of a relevant (abstract) concept with (concrete) empirical evidence-which may relate to both individual and collective actors - on the basis of the mediation of a series of relevant notions, increasingly close to historical directness ("medium-range" categories). The more this sequence is, among other things, complete, the more successful the explanation will be. Abstraction (concept) is stated to be the starting point, because that is what it always is in science, in contrast to commonsense opinion, which starts and ends with directness. ${ }^{12}$ Thus empirical research of intergenerational and intragenerational changes of positions in the occupations of individuals inevitably start from the concept of social mobility.

A focus on our narrower subject reveals the following. To approach the definition of the concept of class it is necessary to start from an assumption of a higher order of abstraction, which is the following: global social systems/ social formations (feudal society, capitalism, real socialism, etc.) are based on the domination of a specific mode of social life production. This is always accompanied by others which appear as remains of the past, or "in potency," and may represent alternatives to the existing dominant mode of production. Due to possible misunderstandings created as a rule by a reductionist understanding of the Marxist approach to social analysis (by both its critics and supporters) from the tradition of which this concept originates, the following comments should be made. The concept of the mode of production of society does not refer to the economic roots of each and every social order, but to the following interrelated series of assumptions:

1. fundamental social relations are products of human action;

2. this production develops in spheres of:

a. the material reproduction of society

b. the reproduction of forms of regulation/control of hierarchical social integration,

c. the reproduction of forms of symbolic communication;

3. the forms of these three reproduction practices are in different ways systemically integrated into different social formations.

12 Representations of commonsensical directness are referred to by Kosik as the world of pseudoconcreteness: “... In destroying the pseudo-concrete, dialectical thinking does not deny the existence of the objective character of these phenomena, but rather abolishes their fictitious independence by demonstrating their mediateness" (1976: 40). 
The global division of labour within the frameworks of these formations is established primarily depending on the control of overall conditions of the dominant mode of social production in the spheres of economic ownership, political/state authority, and cultural hegemony. It is precisely this division of labour, sustained in relatively lasting forms, which is revealed as the class division of society.

A general connection between the conditions of reproduction of a given/dominant mode of production of society, expressed as the systemic interdependence of economic, political and cultural relations in a society, is necessary to sustain it, because class division essentially represents an order of inequality and domination. This systemic interdependence-the mutual conditionality of assumptions of economic, political and cultural domination, i.e. subordination-leads to a situation where at the global social level class division takes the form of antagonism between two main social classes. This initial general insight, however, must be supplemented in further historical research with the following inferences. In a concrete-historical existence, as already mentioned, the mode of production of social life is not and cannot be "pure" (due to the existence of elements of past and potential/alternative modes of production). Moreover, economic, political and cultural forms of domination have only a systemic link, rather than an identity, because this link takes different degrees in different modes of social production. Furthermore, in their concrete manifestations overall and individual forms of domination are revealed as partial (let us recall only the different status of slaves in ancient societies, or serfs and freemen in feudal society, etc.), which means that they reach a certain level on a dis/continuity scale. All this, finally, means that the basic two-class opposition, as a general characteristic of the mode of a society's production, is in a concrete-historical sphere broken down into different forms of systems of class relations. In other words, in historically given systems of social relations the two-class system dissolves into multiclass systems, and classes themselves appear as complex groups composed of a larger number of subgroups (strata).

Therefore, any theoretical position on classes must take into account the following facts. The concept of class - its general definition, as well as specific characteristics of class relations, including the modes of action-cannot be defined in the same manner at different levels of abstraction wherein socialhistorical analysis operates. Namely, this analysis may take place on at least four theoretical levels, which form different analytical frameworks:

a. a global framework of the mode of production of social life;

b. a framework of the social-historical system;

c. a framework of the concrete-historical form of reproduction of a specific society; 
d. a framework of the everyday life of individuals who form a specific social group (class).

It is quite clear that conceptual instruments at these different analytical levels definitely cannot be identical, but must be differentiated in a way which will retain the consistency of the analytical apparatus in the process of differentiation. The following paragraphs will in brief terms show how class may be determined at each of the above-mentioned analytical levels, starting from the most general to increasingly concrete research plans.

\section{Class in the analytical framework of the mode of production of a social life}

At the most abstract analytical level, classes appear as social groups formed on the basis of a global social division of labour. This division leads to antagonism between the groups depending on the control of basic conditions of reproduction of the given mode of social life production. Bearing in mind that, historically speaking, the conditions necessary for the reproduction of a society (land or capital, for example) appear as scarce resources, their distribution is necessarily unequal. This is why in the process of production/distribution a monopoly of one group in control of these resources must inevitably appear (including resources for the securing of the monopoly and of its legitimization), as opposed to the exclusion of the other group from this control, on the basis of which relations of domination/subordination are formed. In other words, continuance of the existing mode of reproduction of society implies that a relation of monopoly/exclusion (domination/subordination) is established as relatively lasting, whereby classes are formed by groups who possess that monopoly, or are excluded from the possession thereof (dominant vs. subordinate group). In that sense they appear as internally unified in terms of the relation of monopoly/exclusion, as well as mutually antagonistic. Therefore, the basic interests of these groups may be determined as structurally formed tendencies to retain (discontinue) the basic relation of monopoly/exclusion (domination/subordination). These interests appear as general factors in the internal unification of classes, which at the same time make them mutually opposed (and that is the analytical level Marx retains in his Manifesto).

It is therefore important to bear in mind that only in this most general sense can we claim that historical social formations (feudal society, capitalism, real socialism, etc.) rest on the contrariety of two basic classes whose antagonism determines the main lines of social processes (reproduction of the given 
mode of production, social conflicts, social changes, etc.). At this analytical level, classes are most often part of the conceptual apparatus in studies that analyse the processes of the establishment of a new-or the destruction of the existing - mode of production of social life and the fundamental relations of the given social formation. In that sense the historicity of a social formation is manifested as a process of its creation and, consequently, its inevitable disappearance. Typical examples of these processes, as well as studies which address them, include transformation of forms of extended personal dependence (feudal society) into relations of limited, economic, dependence (the creation of personally free workers, unlimited disposal of private ownership, etc.; Aston and Philpin eds. 1987); a formation of the "ethos of vocation" (Weber 2003); civilizing (Elias 1978); the suppression of forms of action based on passions by interest-based action (Hirschman 1977), etc.

\section{Class in the analytical framework of the historical system of social relations}

In analyses which operate within more concrete research plans, the global social division of labour is manifested as a distribution of the means of material production, means of control of (coercive) social integration, and the means of systemic legitimation; i.e., is expressed in the form of social relations as a division of economic- (ownership), organizational- (political), and cultural resources. Thus, at this analytical level, where the capitalist social formationfor example - appears as a capitalist historical system of social relations, classes may be defined as social groups which hold, or are deprived of, ownership of the means of economic re/production, control of the means of political domination, and of the means of cultural hegemony.

The starting analytical point here is the following. A social system represents a complex entity composed of basic subsystems (economic, political, cultural), while these subsystems may mutually interrelate in different ways (and their determinational relations are also changeable). They may be mutually integrated, so that all three subsystems are predominantly merged (as in the feudal, or real socialist orders), or mutually autonomous to a remarkable degree (as in the capitalist order). This is why now the initially "dual" (antagonistic) class relations differentiate into more complex structures, while the initially unique corpus of the class is revealed as internally complex, and composed of subgroups (strata, factions, etc.). These subgroups are formed in subsystems wherein specific rules of reproduction are maintained (but only within the frameworks primarily given by overall conditions of reproduction of the dominant mode 
of social life production), thus also producing a differentiation of unique class interests. The securing of overall conditions of reproduction of the capitalist mode of production may, for example, in a specific historical system of relations involve the effort to strengthen the assumptions of political domination of the ruling class (more precisely, domination of its particular stratum which controls organizational resources; i.e. wields political power) by creating in the sphere of material distribution (thus within the economic subsystem) an increased share of income for non-owner groups at the expense of owner profits ("welfare state"). Class interests are here formed as structurally based trends, but arewithin wider frameworks of the orientation towards maintenance/abolishment of overall relations of domination - now based on the preservation/change of the special conditions for the reproduction of class subgroups (strata). Studies of the possibilities for a relatively autonomous role of the state in capitalism written by Moor (1966), Skocpol (1979), Tilly (1990) and other authors belong to analyses of this type, as do the studies on welfare state regimes by Marshall (1992) and Esping-Andersen (1990).

It is clear that historicity at this analytical level appears in a more pronounced form as a diachronous as well as synchronous change of systemic assumptions about social reproduction in the form of different mutual relations of individual subsystems. Thus, from a diachronical perspective, different degrees of integration of economic and political subsystems may be observed in capitalism: from early forms with a more forceful integrative role of the mercantile state through the pronounced self-regulatory role of the market in the liberal period, the strengthening of the interventionist state during the twentieth century, to the modern neoliberal period. These different forms of systemic integration also appear at the synchronous level and form the basis for references to AngloSaxon, German, Japanese, etc. capitalisms (Gilpin 2001; Coates ed. 2005). In the same way, systemic integration in the economically most developed centre of capitalism in the form of economic self-regulation as a rule differs from the more prominent political mediation in less developed areas.

\section{Class in the analytical framework of a concrete-historical society}

Further towards the concretization of analytical frameworks, where they reach the level of a concrete-historical society (US capitalist society, Yugoslav "liberal socialism," etc.), the concept of class and class relations is further differentiated on the basis of two specific factors.

Firstly, as already emphasized, at the concrete-historical level a specific mode of production of social life is established as dominant, meaning that it is, as a 
rule, accompanied by elements of other past as well as potentially new modes of production (those that can be established, or those which in retrospective analysis have been established after the given one). On the basis of these subordinated but actually present social forms, specific groups are also formed. They may have different relations towards the basic classes (formed, in the previously defined sense, on assumptions of the reproduction of the dominant mode of production). For example, Tocqueville (1955) demonstrated that for decades after the revolution in France the ancient regime was present through its institutions as well as in parts of the aristocracy who played an important political role in cooperating with bourgeoisie or opposing it, merging with it or separating from it. Analogously, and approximately at the same time, Robert Owen in Britain organized New Lanark based on principles deduced from a possible type of society (Polanyi 2001).

However, still more important is the second factor, which derives from the above-mentioned differentiation of three social subsystems-economic, political and cultural. These sub-systems create internal unities and are mutually systemically connected, but their structures are not identical. They are namely themselves internally differentiated, because the distribution of resources within them in the spheres of material production, (coercive) social integration and systemic legitimation is hierarchical. Ownership (or economic resources), power (or organizational resources) and cultural resources are unevenly distributed. The unequal distribution of resources is characteristic of the dominant social class (large, medium and small owners). Moreover, control over resources does not necessarily remain within the borders of that class (although it must manage the substantial majority of resources necessary for the reproduction of the given conditions of social life in order to be called dominant at all). The economic capital of modern corporative capitalism has thus partly "spilled over" into the hands of shareholders who belong to the strata of middle level- and even manual workers (as long ago demonstrated in a classic study by Berle and Means (1968), just as the most prominent political positions in Germany or Austria were until a hundred or so years ago held by the representatives of the old regime. Furthermore, while the overall distribution of organizational resources in a society ensures the reproduction of the dominant form of class relations, factions that hold political power in different historical periods particularly promote the interests of the members of one or the other economically dominant faction of the ruling class (to the extent that overall class interests are not jeopardized; see a well-known study by Chandler [1979]). In addition, political domination may be imposed by special actors on the dominant class as a whole, again in a way which does not endanger the reproduction of the dominant mode of production (this historical phenomenon was addressed by Marx [2005], showing that Louis 
Bonaparte grounded his autocratic rule within a capitalist mode of production on the lowest class of French society, the peasantry). It may also protect the interests of subordinate social classes, contrary to the aspirations of a substantial part of the ruling class (as, for example, in the case of the introduction of welfare state policies).

Class interests are thus at this analytical level also revealed as partially differentiated (although they are here still understood as structurally based), so that classes themselves appear as internally divided, and even potentially conflictive, entities. Intraclass conflicts, however, appear as competitive rather than antagonistic. This is the case of conflicts concerning the redistribution of resources, rather than the maintenance/abolishment of the bases of their appropriation; i.e., control. In that framework, classes may be defined as social groups which are reproduced in similar life conditions (whose members have a similar education, way of life and life chances), and therefore have common interests. The mutual concordance of these interests is not necessarily allcomprising in everyday life, and appears only in a general sense, rather than directly (therefore, this does not only speak of the "contradictory class locations" addressed by Wright [1985] but class characteristics themselves at this analytical level appear as inconsistent), while general class interests remain in principle opposed to interests of the antagonistic class.

At this analytical level the previous antagonism of class relations is broken down into overlapping systems of inter- and intra-class relations. Strata (factions, etc.) within a class may, for example due to different interests, enter into mutual conflicts. Thus conflicts emerge between large and small capital, skilled and unskilled workers, etc. As already mentioned, however, interest differences, and even intraclass conflicts, have an internal limit, which is given by the previously identified, more general interest in maintaining/changing the overall position of the group in the given conditions of reproduction of the dominant mode of production of society: preservation of private ownership, relations of personal dependence, etc. On the other hand, individual factions of different/ antagonistic classes may establish short-term or more lasting coalitions with a view to achieving complementary interests (in this sense, Scott [1992] analyses the formation of a class block between capitalists and parts of the middle class in Great Britain by means of which the ruling class ensures its political domination; the above-mentioned differentiation of "contradictory class location" by E.O. Wright also belongs to this analytical level).

Thus class relations now appear as multiply determined by a combination of historical and conjunctural factors, which is why the former research approach is partly inverted at this analytical level. The problem is no longer the analysis of class relations on the basis of the overall social (structural) position of class, but 
it appears necessary to show how specific group situations (concrete-historical conditions of the reproduction of classes and parts thereof, their mutually antagonistic interests, as well as competitive interests of parts of classes) are reconstituted into a single class position. This analytical level is most often reached when, as commonly seen in historiography, or in "statistically reconstructive sociology," an attempt is made to (subsequently) advance from a descriptive representation and facts as records of the directness of everyday life to a conceptually founded explanation (we have already seen that Savage could not, and indeed failed to, overcome this difficulty). In that sense, historicity, or empirically established social theory, is then revealed as an attempt to fix a hardly discernible cacophony of current events, which due to its continuous vague changeability is precisely shown as essentially static.

\section{Class at the analytical level of everyday life}

Finally, at the level of everyday existence of members of a certain society, classes appear as large groups of individuals who, sharing similar life conditions and life trajectories, form similar patterns of behaviour, social consciousness, etc. General features, derived from the characteristics of the given system of social relations, are here revealed only as tendencies which have a certain statistical regularity, but in each individual case appear accidentally. Borders between classes at this analytical level appear as provisional and permeable, and the class structure is shown as an intertwining of continuing hierarchies which only partly (sometimes more, sometimes less) overlap. Furthermore, within this intertwining an individual may occupy different hierarchical positions in view of different features such as the disposal of various resources (family status, income, education, political power, reputation; or economic, organizational, cultural resources; stratification studies in a standard functionalist theoretical framework adhere to this research plan as a rule, and the majority of those that criticize the class approach - as entirely inadequate or obsolete - use the data collected in research thus conceived; finally, we have witnessed an abortive attempt by Savage to use that kind of approach himself).

In view of a large number of factors which determine the position of (concrete) individual members of a class, as well as the nonexistence of the necessary interconnection between these factors, the mobility of individuals within position hierarchies (vertical mobility) is possible and they may have different perceptions of their personal and group interests, as well as overall social conditions, and may support different political orientations (for the phenomenon of variability of class votes, see Hout, Brooks and Manza 1993; Evans, ed. 
1999; Goldthorp, 1999), etc. In brief, the central subject of research is now the individual, whose membership of a group must be analytically reconstructed, which is a field of operation of empirical sociology. It is there established that the interests of individuals may be structured on different bases. Workers in one capitalist firm, for example, may have interests which are: a. competitive compared with other workers in that firm, involving vying for a work place, size of wage, etc.; b. shared with other workers and opposed to the interests of employers in conflicts concerning appropriations of the firm's revenue for the wage fund, investments, dividends, etc.; c. shared with other workers and employers of the firm and opposed to the interests of workers and employers of other firms under conditions of market competition; $d$. shared with other workers and employers within one country and opposed to the interests of workers from other countries under conditions of international market competition, etc. In addition, it is empirically possible to establish the existence of problems in the perception of individuals' own interests. Individualist ideology, for example, leads to a situation wherein workers may consider themselves - rather than the character of social relations - responsible for unemployment, or for low income; i.e., for their own poor market prospects.

Finally, it is also empirically possible to observe an endless idiosyncrasy of "personal equations" whereby every decision or consequent act may be interpreted as the expression of subjectivity on the basis of an anthropologically given individuality. Just as at this analytical level groups may be reconstructed on different bases, including those of class, so are the interests understood as interpreted by individuals. Social history now disappears from the analytical horizon and is substituted by eventfulness.

\section{FINAL REMARKS}

What should be borne in mind in relation to the overall discussion above is the fact that conceptual delimitations within the frameworks of above-mentioned analytical levels are feasible only in one direction: from general toward individual. In other words, the empirical analysis of given social relations as the epistemological starting point cannot lead to the reconstruction of the concept of class on the most general level; i.e. it may only be conducive to always partial empirical generalizations. On the other hand, this does not mean that its overall scientific status is second-rate, because everyday life cannot be interpreted as the epiphenomenon of overall historical structural movements. This is not only to say that the validity of theoretical derivations lies primarily in the research 
fertility they ensure and encourage, but also that the validity of the conceptual analysis must find its confirmation in tendentional regularities formed at the eventfulness level, which, through lasting ("longue duree") existence, constitute the general structural characteristics of social relations that form the starting point of theoretical inference.

Another important thing to bear in mind is that analytical levels are here separated on the principle of economy, which means that elementary, theoretically necessary analytical differentiation has been introduced. The levels of mediation between the most abstract and direct-phenomenal level could be additionally increased or decreased, depending on analytical needs and the specific subject of research. For example, following the level of the "historical system," the division between central, semi-peripheral and peripheral types of capitalist systems as the next analytical step may be introduced, etc.

In relation to our basic subject we may take as established that the concept of class inevitably "extends" to all above-mentioned analytical levels; i.e., to the whole epistemological "space" where the research into fundamental social relations of inequality takes place. This also means that the specific class analyses, revolving primarily at one of analytical levels, must be mindful of the contents of the class concept at other levels general or less general than those being researched.

Obviously, the definition of the class concept at each of these levels must be different due to added specific characteristics at each subsequent concrete level, although these specific features clearly must be consistent with the more general definition. Thus, in a strict sense, we could say that the concept of class may fully be defined only as a synthetic category which encompasses the totality of definitions of various levels of abstractness. Naturally, in the case of concrete studies this request may be difficult to comply with, and even perhaps unnecessary if the principle of totality itself is borne in mind and reductionist traps or non-systematic movement through different levels of analysis are avoided. The same applies to the criticism of the class approach in the study of social relations. It is completely off the mark if aimed at the totality of approach with only one analytical level in mind. Naturally, under the condition that the adherents of that approach do not so enable it, thereby overlooking the whole epistemological field upon which the class analysis must unfold. 


\section{REFERENCES}

Aston, T.H. and Philpin, C.H.E, eds. (1987). The Brenner Debate. Agrarian Class Structure and Economic Development in Pre-industrial Europe. Cambridge: Cambridge University Press.

Beck, U. (1992). Risk Society. Towards a New Modernity. London: Sage Publications.

Berle, A. and Means, G. (1968). The Modern Corporation and Private Property. New York: Harcourt Brace.

Bourdieu, P. (2002/1984). Distinction - A Social Critique of the Judgement of Taste. London: Routledge Kegan Paul.

Chan, T.W. and Goldthorpe, J.H. (2007). Class and Status: The Conceptual Distinction and its Empirical Relevance. American Sociological Review,72 (4), 512-532.

Coates, D. ed. (2005). Varieties of Capitalism, Varieties of Approaches. Basingstoke: Palgrave Macmillan.

Crompton, R. (2008/1993). Class and Stratification (Third Edition). Cambridge: Polity Press.

Dahrendorf, R. (1959). Class and Class Conflict in the Industrial Society. London: Routledge.

Durkheim, E. (1982). The Rules of Sociological Method. New York, London, Toronto, Sydney: The Free Press.

Elias, N. (1978). The Civilizing Process. Oxford: Blackwell.

Erikson, R. and Goldthorpe,J.H. (1992). The Constant Flux. Oxford: Clarendon Press.

Esping-Andersen, G. (1990). The Three Worlds of Welfare Capitalism. Princeton: Princeton University Press.

Evans, G. ed. (1999). The End of Class Politics: Class Voting in Comparative Context. Oxford Scholarship Online Monographs.

Fukuyama, F.(1992). The End of History and the Last Man. London: Penguin.

Giddens, A. (1995). The Constitution of Society. Outline of the Theory of Structuration. Cambridge: Polity Press.

Gilpin, R. (2001). Global Political Economy. Princeton: Princeton University Press.

Goldthorpe, J. H.(1996). Class Analysis and the Reorientation of Class Theory: The Case of Persisting Differentials in Educational Attainment. The British Journal of Sociology, 47 (3), 481-505 (Special Issue for Lockwood).

Goldthorpe, J. H.(1999). Modelling the Pattern of Class Voting in British Elections, 1964-1992, in G. Evans, ed. The End of Class Politics: Class Voting in Comparative Context.(pp. 59-82). Oxford Scholarship Online Monographs. 
Goldthorpe, J. H. (2007/2000). On Sociology (The Second Edition). Stanford, CA: Stanford University Press.

Goldthorpe, J. H., McKnight, A. (2004). The economic basis of social class. London: Centre for Analysis of Social Exclusion, London School of Economics.

Gramsci, A. (1971). Selections from the Prison Notebooks of Antonio Gramsci, edited and translated by Q. Hoare and G.N. Smith. New York: International Publishers.

Hirschman, A. (1997). The Passions and the Interests: Political Arguments for Capitalism before Its Triumph. Princeton, N.J.: Princeton University Press.

Hout, M., Brooks, C. and Manza, J. (1993).“The Persistence of Classes in Postindustrial Societies". International Sociology, 8 (3), 259-277.

Kosik, K. (1976). Dialectics of the Concrete. Dordrecht, Boston: D. Reidel Publishing Company.

Lash, S. (1990). Sociology of Postmodernism. London: Routledge.

Lazic, M. \& Cvejic, S. (2007). Class and Values in Postsocialist Transformation in Serbia. International Journal of Sociology, 37 (3), 54-74.

Marshall, G. (1997). Repositioning Class. London: SAGE Publications.

Marshall, T.H., Bottomore T. (1992). Citizenship and Social Class. London: Pluto Press.

Marx, K. (2005). The Eighteenth Brumaire of Louis Bonaparte. New York, Berlin: Mondial.

Marx, K. and Engels, F. (2012). The Communist Manifesto. A Modern Edition. London: Verso.

Mills, C. (2014). "The Great British Class Fiasco: A Comment on Savage et al." Sociology 48(3), 437-444.

Mills, C. (2015). "The Great British Class Survey: Requiescat in pace". The Sociological Review 63(2), 393-399.

Moore, B. (1966). Social Origins of Dictatorship and Democracy: Lord and Peasant in the Making of the Modern World, Boston: Beacon Press.

Nagel, E.(1961). The Structure of Science. New York Burlingame: Harcourt, Brace \& World.

Pakulski, J and Waters, M. (1996). The Reshaping and Dissolution of Social Class in Advanced Society. Theory and Society, 25(5), 667-691.

Piketty, T. (2014). Capital in the Twenty-First Century. Cambridge MA, London: The Belknap Press of the Harvard University Press.

Polanyi, K. (2001/1944). The Great Transformation: The Political and Economic Origins of Our Time, 2nd ed. Boston: Beacon Press.

Savage, M. et al. (2013). "A New Model of Social Class? Findings from the BBC's Great British Class Survey Experiment," Sociology 47(2), 219-250. 
Savage, M. et al. (2015). Social Class in the 21 $1^{s t}$ Century. London: Penguin, Random House.

Chandler, A. (1977). The Visible Hand. Cambridge: The Belknap Press of Harvard University Press.

Skocpol, T. (1979). States and Social Revolutions. Cambridge: Cambridge University Press.

Scott, J. (1992). Who Rules Britain? Cambridge: Polity Press.

The Sociological Review. (2015). Special Issue: Sociologies of Class: Elites (GBCS) and Critiques, 63(2), 205-549.

Sztompka, P. (1994). The Sociology of Social Change. Cambridge Mass.: Blackwell.

Tilly, C. (1990). Coercion, Capital and European States AD 990-1990. Oxford: Basil Blackwell.

Tocqueville, A. (1955). The Old Regime and the French Revolution. New York: Anchor Books.

Weber, M. (1978). Economy and Society: An Outline of Interpretive Sociology. Berkley, CA: University of California Press.

Weber, M. (2003/1958). The Protestant Ethic and the Spirit of Capitalism. Mineola, New York: Dover Publications.

Wright, E.O. (1978). Class, Crisis and the State. London: New Left Books.

Wright, E.O. 1985. Classes. London: Verso.

Wright, E.O. and Martin, B. (1987). The transformation of the American class structure, 1960-1980. American Journal of Sociology, 93(1), 1-29.

Wright, E.O. et al. (1989). The Debate on Classes. London: Verso.

Wright, E. O. ed. (2005). Approaches to Class Analysis. Cambridge: Cambridge University Press.

Wright, E. O. (2015). Understanding Class. London: Verso. 